\title{
Implementasi Metode UCD (User Centered Design) Pada Rancang Bangun Sistem Informasi Perpustakaan: Studi Kasus : SMK Negeri 1 Gelumbang
}

\author{
Ekta Noviyanti, Andi Christian \& Khana Wijaya \\ STMIK Prabumulih \\ Email: ektanoviyanti97@gmail.com
}

\begin{abstract}
Libraries play an important role in advancing the institute of education because the library is a place to improve knowledge for the students. In the library of SMK Negeri 1 Gelumbang running processes such as member registration, input data on prospective member, borrowing and returning books, book data input and book catalog still written in the ledger. Avoid delays in the system library service SMK Negeri 1 Gelumbang, it is necessary to design an information system library that can help and easier the activities of the circulation of the books. In the information system library SMK Negeri 1 Gelumbang uses (User Centered Design) dan UML (Unified Modeling Language) as well as for language programmer PHP with a MySQL database.Hopefully with this library information system it can solve the problems which exist in the library and can help in the development of science students.
\end{abstract}

KeyWords : PHP, libraries, (User Centered Design) dan UML (Unified Modeling Language)

\section{Pendahuluan}

Pendidikan merupakan salah satu pilar untuk menunjang kemajuan suatu bangsa. Proses belajar mengajar menjadi proses yang sangat penting dalam pengembangan dunia pendidikan. Untuk menunjang proses belajar mengajar tersebut memerlukan referensi baca yang baik berupa buku, kamus, majalah, dan sumber bacaan lain. (Diah Puspitasari, 2016). Perpustakaan merupakan tempat untuk mencari ilmu, menemukan referensi dan menyimpan bahan pustaka yang digunakan oleh manusia untuk mencari informasi. Semakin banyaknya buku dan cepatnya perkembangan ilmu pengetahuan membuat para pembaca mengalami kesulitan dalam pencarian buku. Tidak semua pembaca mempunyai banyak waktu untuk berkunjung ke perpustakaan untuk mencari buku referensi yang dibutuhkan. (Sri Surmalinda, 2014)

Perpustakaan SMK Negeri 1 Gelumbang memiliki peralatan dan perlengkapan yang memadai. Serta siswa atau siswi telah diwajibkan menjadi anggota perpustakaan sekolah. Namun proses pelayanan yang dilakukan masih secara konvensional yaitu semua pendataannya masih ditulis dalam buku besar dan saat mencari data buku yang dibutuhkan harus membuka satu per satu halaman buku, hal tersebut menyebabkan lambatnya dalam pencarian data, layanan sirkulasi ataupun pembuatan laporan sistem ini sudah dianggap tidak efisien lag imengingat pesatnya peningkatan jumlah judul dan jumlah buku untuk mengatasi permasalahan tersebut diperlukan suatu sistem informasi. Untuk memenuhi pelayanan yang baik dan efisien terhadap para anggotanya, perpustakaan memerlukan suatu sistem informasi yang dapat membantu para anggota dalam mencari informasi atau referensi tentang data-data yang diperlukan.

Sistem informasi yang harus dilakukan yaitu pendaftaran anggota, proses penginputan 
data calon anggota, proses pengunjung, proses peminjaman dan pengembalian buku, proses penginputan data buku dan catalog buku pada perpustakaan SMK Negeri 1 Gelumbang masih belum menerapkan sistem informasi karena pada perpustakaan ini masih secara konvensional pada buku besar. Dengan menarapkan sistem informasi ini diharapkan para pengunjung dan pembaca tidak ada kendala lagi.

Berdasarkan latar belakang masalah diatas maka penulis tertarik mengimplementasi metode UCD (User Centered Design) pada rancang bangun sistem informasi perpustakaan (studi kasus : SMK Negeri 1 Gelumbang).

\section{Tinjauan Literatur}

\subsection{Pengertian Implementasi}

Menurut Indrajani (2017:1), implementasi merupakan realisasi fisik dari basis data dan desain aplikasi yang dicapai dengan menggunakan DDL untuk

membuat skema basis data dan database file yang kosong.

\subsection{Pengertian UCD (User Centered Design)}

Menurut Intan Sandra Yatana Saputri, dkk (2017), UCD adalah sebuah proses desain interface (antarmuka) yang fokus terhadap tujuan kegunaan,

karakteristik pengguna, lingkungan, tugas, dan alur kerja di dalam desainnya.

\subsection{Pengertian Rancang Bangun}

Menurut Fajriyah, dkk (2017), rancang bangun adalah suatu istilah umum untuk membuat atau mendesain suatu objek dari awal pembuatan sampai akhir pembuatan.

\subsection{Pengertian Sistem Informasi}

Menurut Aji Permana (2018), sistem informasi adalah sekumpulan komponen-komponen yang saling berinteraksi untuk mengumpulkan, memanipulasi, menyimpan dan menyediakan informasi yang dapat membantu organisasi untuk mencapai tujuannya.

\subsection{Pengertian Perpustakaan}

Menurut Andi Muh. Lukman (2017), perpustakaan adalah kumpulan atau bangunan fisik sebagai tempat buku dikumpul dan disusun menurut sistem tertentu.

\subsection{Pengertian PHP}

Menurut Betha Sidik (2017:4), "PHP merupakan secara umum dikenal sebagai bahasa pemrograman script script yang membuat dokumen HTML secara on the fly yang dieksekusi di server web, dokumen HTML yang dihasilkan dari suatu aplikasi bukan dokumen $H T M L$ yang dibuat dengan menggunakan editor teks atau editor $H T M L$ ".

\subsection{Pengertian MySQL}

Menurut Fajar Hariadi (2013), mysql adalah sebuah program pembuat dan pengelola database atau sering disebut DBMS (DataBase Management System).

\subsection{Pengertian UML (Unified Modeling Language)}

Menurut Rosa A.S dan M. Shalaludin ( 2015 : 137 ), UML (Unified Modeling Language) adalah bahasa visual untuk pemodelan dan komunikasi sebuah sistem dengan menggunakan diagram dan teks - teks pendukung. 


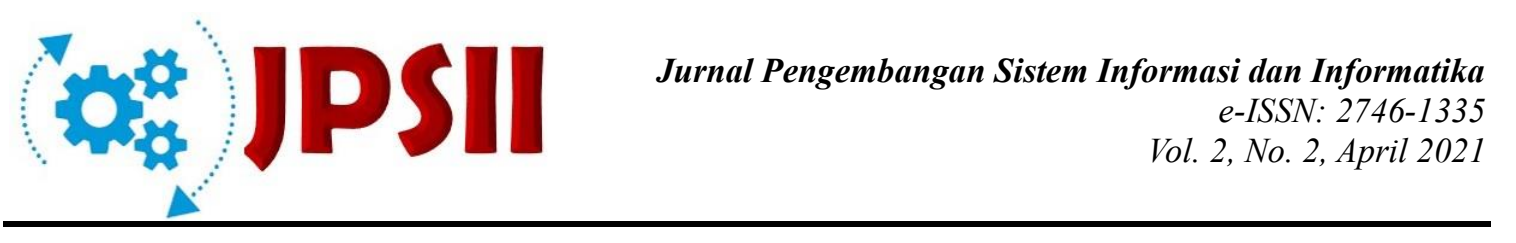

\section{Metode Penelitian}

Menurut Fauzi, Dencik dan Asiati (2019), metode penelitian dapat diartikan sebagai cara ilmiah untuk mendapatkan data yang valid dengan tujuan dapat ditemukan, dikembangkan dan, dan dibuktikan suatu pengetahuan tertentu sehingga dapat digunakan untuk memahami, memecahkan, dan mengatasi masalah.

\subsection{Sumber Data}

Menurut Abdillah Willy (2018:105),"sumber data menjelaskan suatu data penelitian diperoleh.sumber data terbagi atas sumber primer dan sumber sekunder".

\section{Sumber Primer}

Data primer adalah data yang di peroleh dari melalui pihak pertama yang memiliki suatu data.Sumber primer umumnya menunjukan keaslian informasi yang terkandung didalam data tersebut,namun tidak menutup kemungkinan data berkurang keasliannya ketika data telah diolah dan disaji oleh pihak sumber primer. Dalam hal ini sumber data primer diperoleh dengan melakukan pengamatan langsung,wawancara kepada pihak perpustakaan SMK Negeri 1 Gelumbang.

\section{Sumber Sekunder}

Sumber data sekunder adalah data yang diperoleh dari pihak kedua yang ikut mengetahui atau memiliki suatu data.Sumber sekunder dapat diragukan keasliannya karena data telah diolah dan disajikan sesuai dengan kepentingan pemegang data.Dalam hal ini sumber data sekunder diperoleh dari dokumen-dokumen yang telah dikumpulkan oleh pihak perpustakaan SMK Negeri 1 Gelumbang.

\subsection{Teknik Pengumpulan Data}

Menurut Danang Sunyoto (2013:87), metode pengumpulan data adalah cara atau teknik yang dapat digunakan peneliti untuk mengumpulkan data. Adapun metode pengumpulan data yang digunakan dalam penelitian ini yaitu :

1. Wawancara

Wawancara adalah suatu cara pengumpulan data yang digunakan untuk memperoleh informasi langsung dari sumbernya. Pada penelitian ini wawancara dilakukan secara langsung oleh penulis kepada narasumber Ir. Neneng Fajarrahmi sebagai salah satu kepala perpustakaan SMK Negeri 1 Gelumbang.

\section{Observasi}

Observasi adalah suatu teknik atau cara untuk mengumpulkan data dengan jalan mengamati kegiatan yang sedang berlangsung. Pada penelitian ini observasi dilakukan dengan cara datang langsung ke perpustakaan SMK Negeri 1 Gelumbang.

\section{Dokumentasi}

Dokumentasi ditujukan untuk memperoleh data langsung dari tempat penelitian meliputi laporan kegiatan, foto, film, dokumenter, dan data yang relevan dengan penelitian.

4. Studi Pustaka

Studi pustaka adalah pengumpulan data yang dilakukan dengan membaca buku dan referensi lainnya yang berhubungan dengan pembahasan penulis di perpustakaan SMK Negeri 1 Gelumbang. 


\subsection{Metode UCD (User Centered Design)}

Menurut Ambrowati yang dikutip dari jurnal Muslim dan Saifu (2018), Metode UCD merupakan metode pengembangan sistem yang meniti beratkan kepada user sebagai pusat pengembangan sistem, tujuan atau sifat-sifat, konteks serta lingkungan sistem semua didasarkan dari pengalaman pengguna.

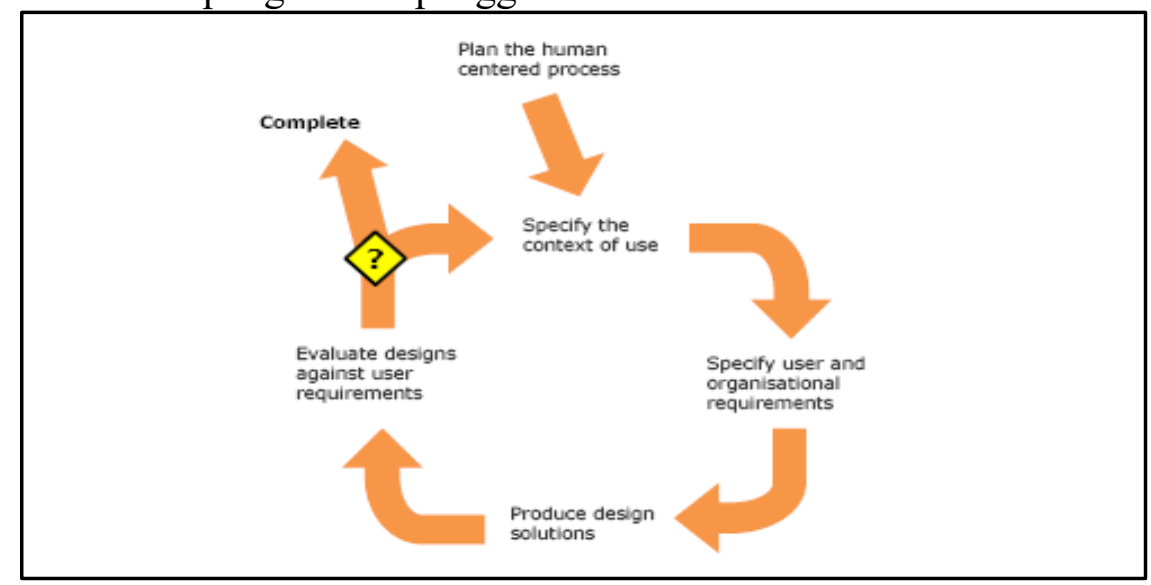

Gambar 3.2 Proses UCD berdasarkan ISO 13407:1999

Sumber : Intan Sandra (2017)

1. Fokus pada Pengguna

Perancangan harus berhubungan langsung dengan pengguna sesungguhnya atau calon pengguna melalui interview, survey, dan partisipasi dalam workshop perancangan.Tujuannya adalah untuk memahami kognisi, karakter, dan sikap pengguna. 2. Perancangan Terintegrasi

Perancangan harus mencakup antarmuka pengguna, sistem bantuan, dukungan teknis seperti perangkat lunak dan perangkat keras yang dibutuhkan serta prosedur untuk instalasi dan pengaturan konfigurasi.

3. Pengujian Pengguna

Satu-satunya pendekatan yang sukses dalam perancangan sistem yang berpusat pada pengguna adalah secara empiris dibutuhkan observasi tentang kelakuan pengguna, evaluasi umpan-balik yang cermat, wawasan pemecahan terhadap masalah yang ada, dan motivasi yang kuatuntuk mengubah rancangan.

4. Perancangan Interaktif

Sistem yang sedang dikembangkan harus didefinisikan, dirancang, dan ditest berulang kali. Berdasarkan hasil test kelakuan dari fungsi.

\subsubsection{Proses $U C D$}

1. Memahami dan menentukan konteks yang akan menggunakan produk.

Ini akan menjelaskan untuk apa dan dalam kondisi seperti apa mereka akan menggunakan produk.

2. Menentukan kebutuhan pengguna dan Organisasi

Mengidentifikasi kebutuhan pengguna dan kebutuhan organisasi

3. Solusi perancangan yang dihasilkan 


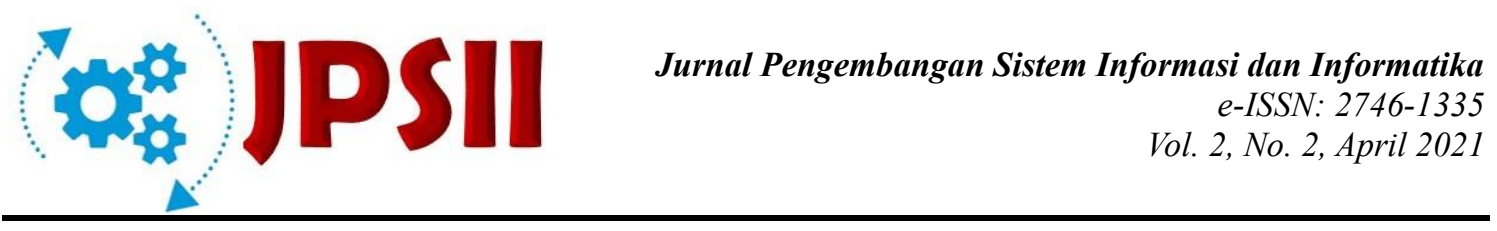

Membangun desain sebagai solusi dari produk yang sedang dianalisis.

4. Evaluasi perancangan terhadap kebutuhan pengguna

Melakukan evaluasi terhadap desain yang dilakukan apakah tujuan pengguna dan organisasi telah tercapai.

\section{Hasil dan Pembahasan}

\subsection{Tampilan Halaman Login}

Berikut adalah tampilan halaman login admin untuk melakukan proses login ke halaman utama.

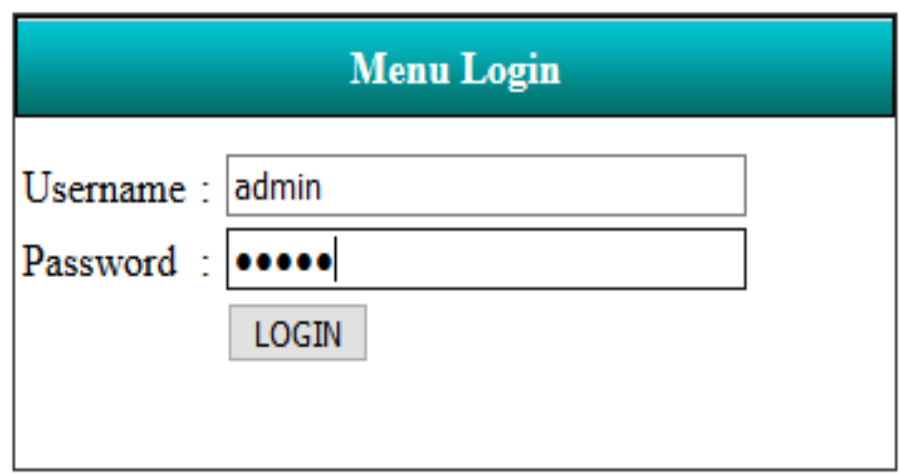

Gambar 4.1 Tampilan Halaman Login

\subsection{Tampilan Halaman Beranda}

Berikut adalah tampilan halaman beranda yang merupakan halaman utama dari sistem, dihalaman beranda terdapat menu-menu yang akan dikelola oleh admin.

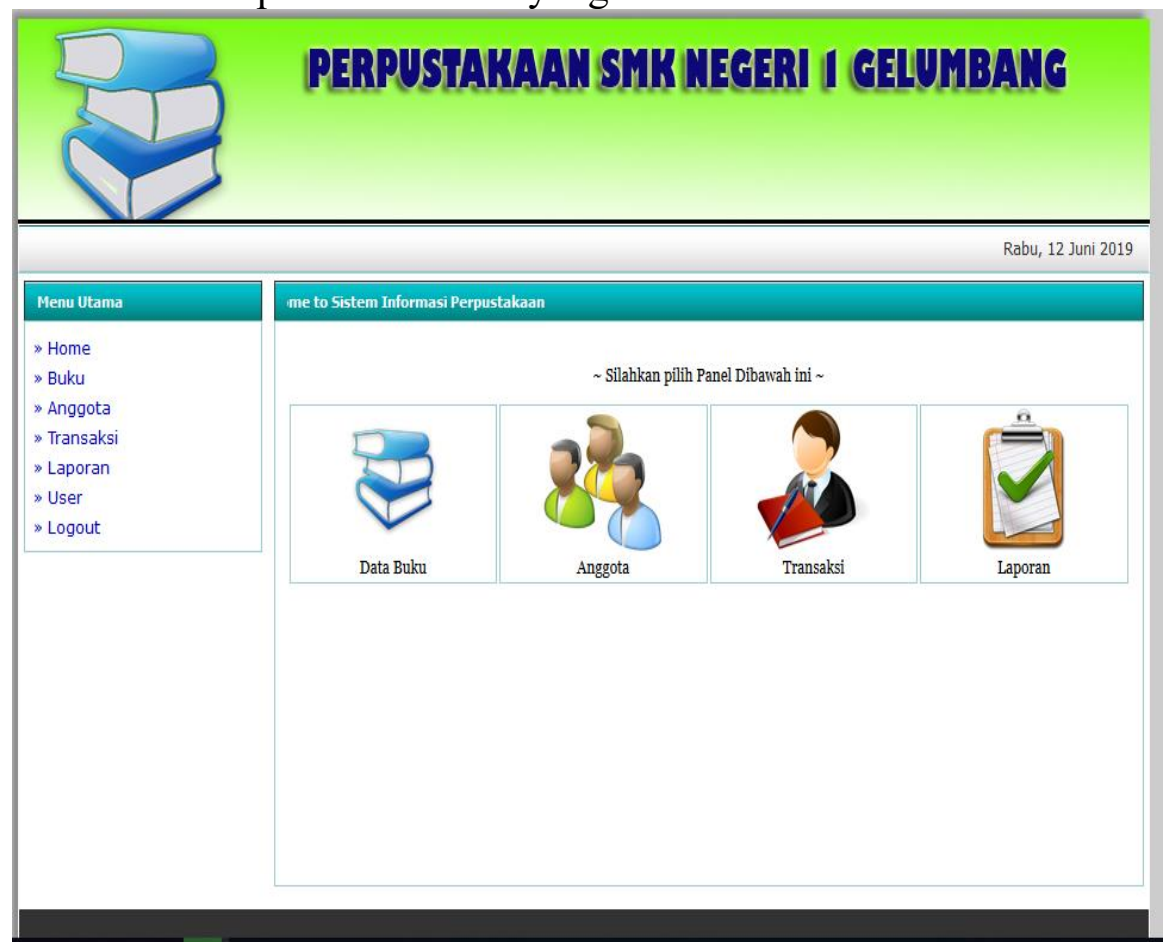

Gambar 4.2 Tampilan Halaman Utama

\subsection{Tampilan Data Buku}

Published by: 
Berikut adalah tampilan halaman data buku yang berisi tentang data buku.

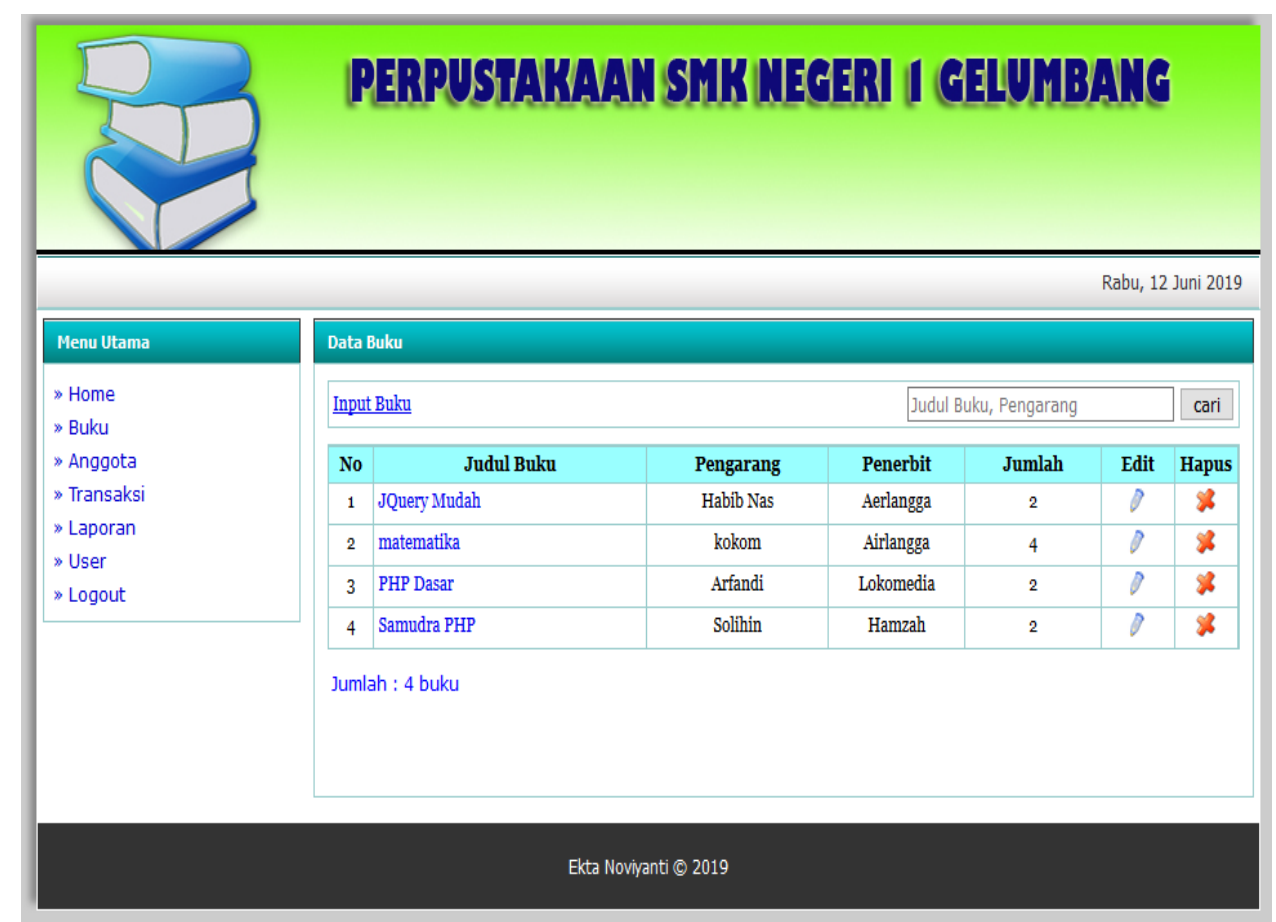

Gambar 4.3 Tampilan Halaman Data Buku

4.4 Tampilan Data Anggota Perpustakaan

Berikut adalah tampilan halaman anggota perpustakaan.

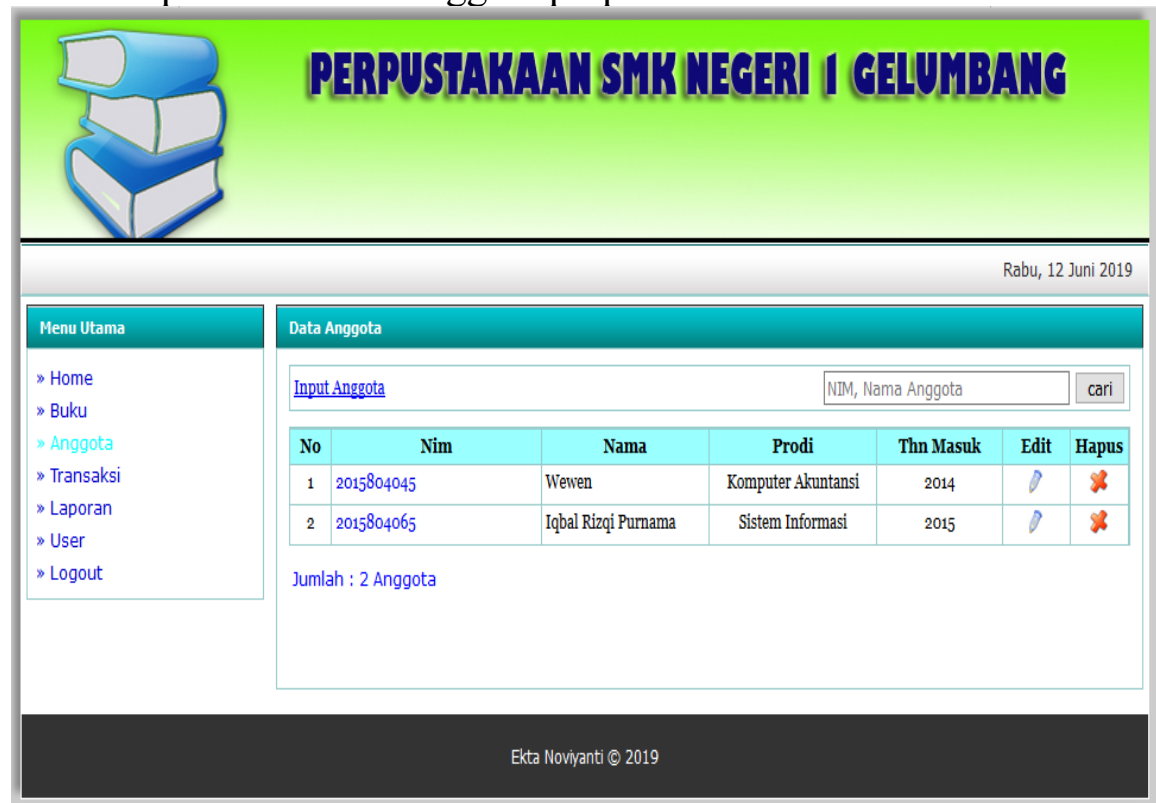

Gambar 4.4 Tampilan Halaman Data Anggota Perpustakaan

\subsection{Tampilan Halaman Data Transaksi}

Berikut adalah tampilan halaman data transaksi yang berisi tentang informasi data peminjaman, pengembalian, dan perpanjangan waktu pinjam buku. 


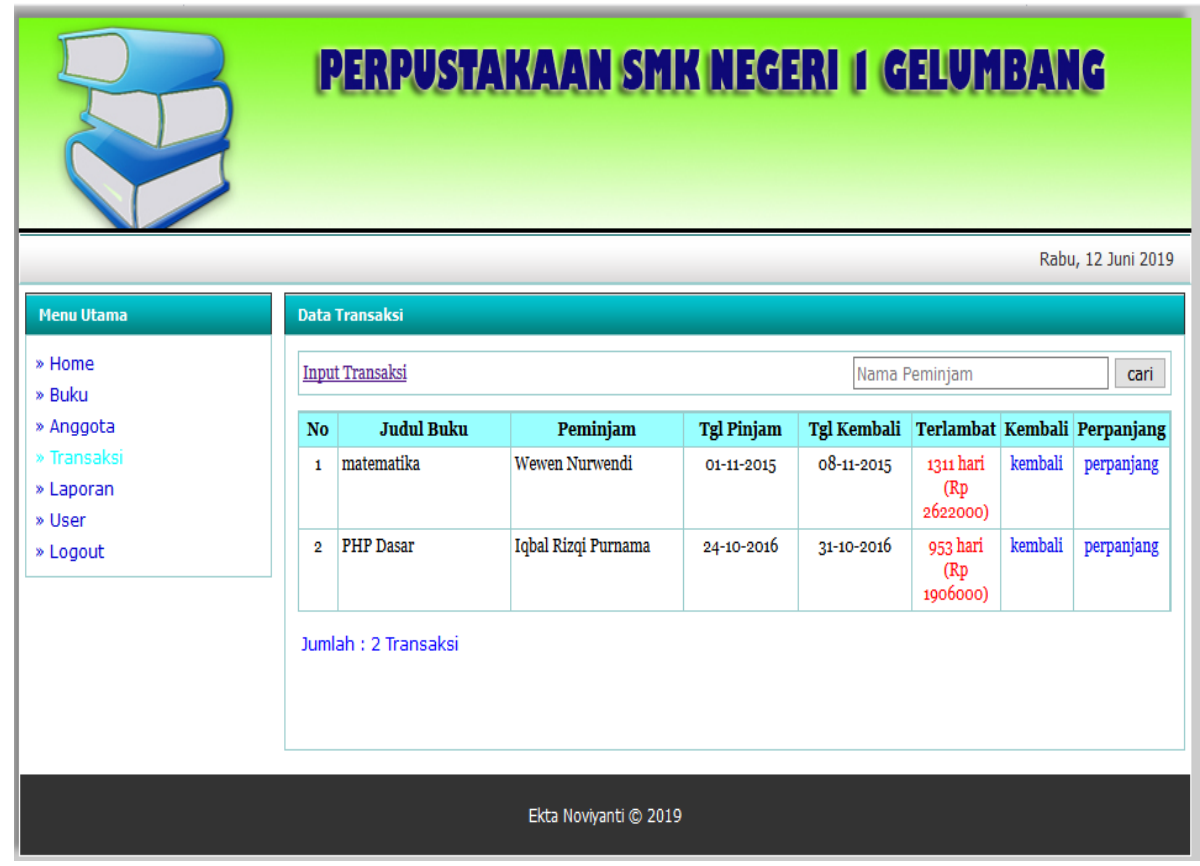

Gambar 4.5 Tampilan Halaman Data Transaksi

4.6 Tampilan Halaman Data Laporan

Berikut adalah tampilan halaman data laporan yang berisi tentang informasi data laporan buku,anggota, dan transaki.

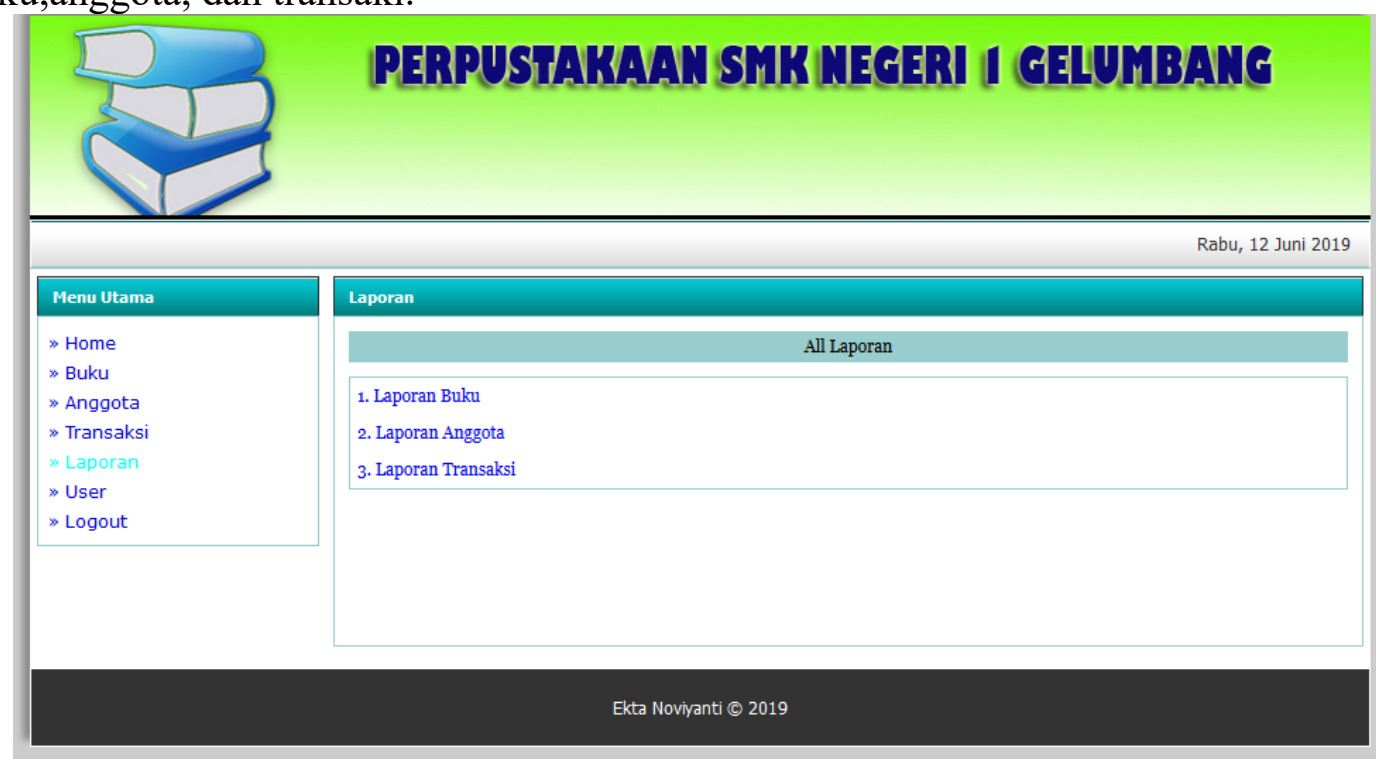

4.7 Tampilan Data User

Gambar 4.6 Tampilan Halaman Data Laporan

Berikut adalah tampilan data user yang berisi tetang informasi data user atau siswa 


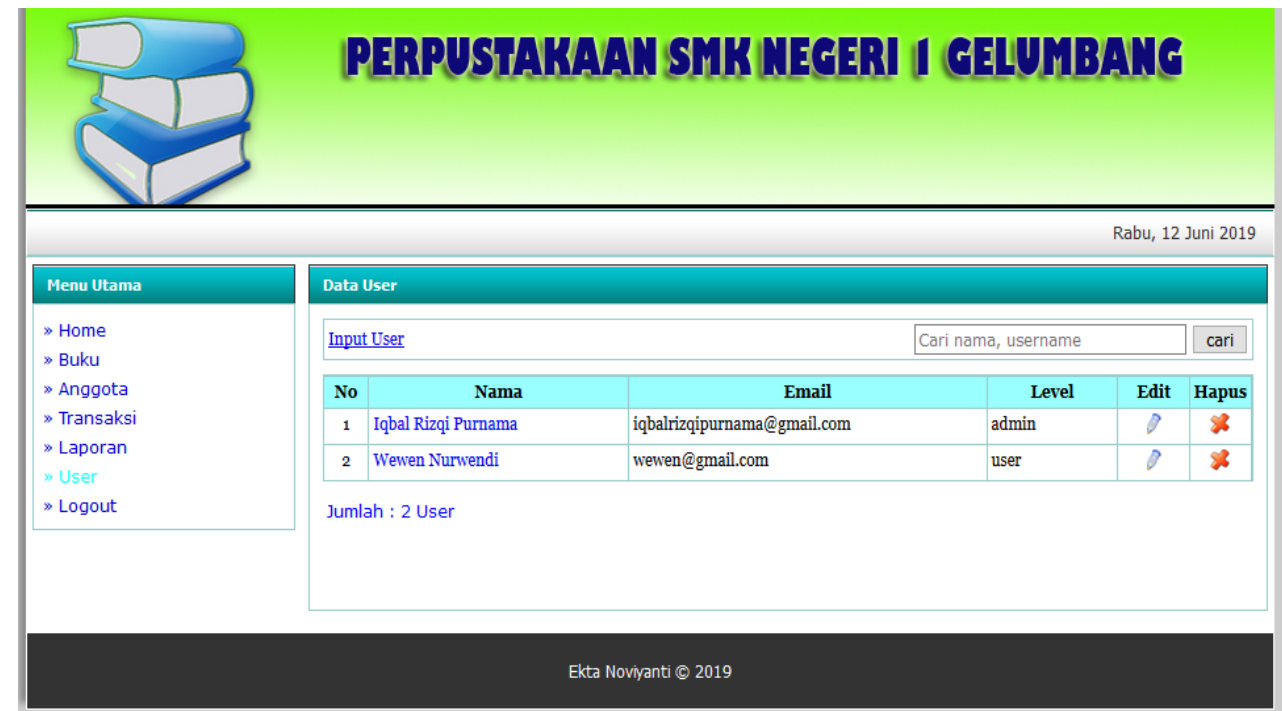

Gambar 4.7 Tampilan Halaman Data User

\section{Kesimpulan}

Sistem informasi perpustakaan SMK Negeri 1 Gelumbang ini dibuat menggunakan pemrograman $P H P$ dan database MySQL dan untuk desain website menggunakan bootstrap. Pada sistem informasi perpustakaan ini terdapat form login, form home, anggota, kategori, buku, peminjaman, pengembalian, laporan, dan halaman logout. Dengan adanya sistem informasi perpustakaan SMK Negeri 1 Gelumbang dapat memudahkan admin dalam penginputan data dan memudahkan siswa dalam peminjaman dan pengembalian buku..

\section{Referensi}

Sidik, Betha. Pemograman Web dengan PHP 7. Bandung: Informatika Bandung, 2017.

A.S. Rosa, M. Shalahudin. Rekayasa Perangkat Lunak Terstruktur dan Berorientasi Objek. Bandung: INFORMATIKA Bandung, 2015.

Abdillah, Willy. 2018. Metode penelitian terpadu sistem Informasi. Yogyakarta : C.V Andi Offset.

Antoni, D., \& Akbar, M. (2019). E-supply chain management value concept for the palm oil industry. Jurnal Sistem Informasi, 15(2), 15-29.

Antoni, D., Fikari, D., \& Akbar, M. (2018). The readiness of palm oil industry in enterprise resource planning. Telkomnika, 16(6), 2692-2702.

Antoni, D., Herdiansyah, M. I., Akbar, M., \& Sumitro, A. (2021). Pengembangan Infrastruktur Jaringan Untuk Meningkatkan Pelayanan Publik di Kota Palembang. JURNAL MEDIA INFORMATIKA BUDIDARMA, 5(4), 1652-1659.

Antoni, D., Jie, F., \& Abareshi, A. (2020). Critical factors in information technology capability for enhancing firm's environmental performance: case of Indonesian ICT sector. International Journal of Agile Systems and Management, 13(2), 159-181.

Fajriyah, Ahmat Josi, Tolip Fisika. "Rancang Bangun Sistem Informasi Tender Karet Desa Jungai Menggunakan Metode Waterfall ." Jurnal SISFOKOM, 2017: 111-115. 
Fauzi, F., Dencik, A. B., \& Asiati, D. I. (2019). Metodologi Penelitian untuk manajemen dan akuntansi. Jakarta: Salemba Empat.

Hariadi, Fajar. "Pembuatan Sistem Informasi Perpustakaan pada SDN Sukoharjo Pacitan Berbasis WEB." IJNS, 2013: 48-54.

Indrajani. Database Design. Jakarta: PT Elex Media Komputindo, 2017.

Intan Sandra Yatana Saputri, Mardhiah Fadhli, Ibnu Surya. "Penerapan Metode UCD (User Centered Design) pada E-Commerce Putri Intan Shop Berbasis Web." Jurnal Nasiona Teknologi dan Sistem Informasi, 2017: 269-278.

Lukman Andi Muh. "Pengembangan Sistem Informasi Perustakaan Umum Menggunakan Inslilite 3.0 di Kab. Enerkang." ILKOM Jurnal Ilmiah, 2017: 70-77.

Permana, Aji. "Rancang Bangun Sistem Informasi Berbasis Web (Studi Kasus : Universitas Kuningan)." Jurnal Cloud Information, 2018: 36-40.

Sugiyono. 2015. Metode Penelitian Kuantitatif, Kualitatif dan R\&D. Alfabeta : Bandung.

Sunyoto Bandung. 2013 . Metode Dan Instrumen Penelitian Ekonomi dan Bisnis. Yogyakarta : CAPS (Center For Academic Publishing Service).

Surmalinda Sri. 2014. Rancang bangun Sistem Informasi Perpustakaan dan Pemanfaatan SMS-Gateway Sebagai Sarana Penunjang Informasi Perpustakaan. Vol : 01 No : 01 2014. ISSN : 2355-5009.

\section{Copyrights}

Copyright for this article is retained by the author(s), with first publication rights granted to the journal.

This is an open-access article distributed under the terms and conditions of the Creative Commons Attribution license (http://creativecommons.org/licenses/by/4.0/) 